\title{
Protecting children from faith-based abuse through accusations of witchcraft and spirit possession: understanding contexts and informing practice
}

\section{Stephen Briggs ${ }^{1}$ and Andrew Whittaker ${ }^{2}$}

\section{Abstract}

Faith-based abuse relating to the practice of witchcraft and spirit possession is a controversial and not well-understood form of child abuse. From its 'discovery' in the UK as a cause of abuse, serious injury and death for children, in 2000 to the present, the recent history of witchcraft and spirit possession involves some high-profile cases, involving serious harm and death for some children, which attracted significant publicity. This article reviews research and commentary, including grey literature, and the emerging policy framework. It discusses the underpinning relationship between faith-based practices and abuse, and takes a post-colonial perspective to discuss the social explanations for the continuing practice of witchcraft and spirit possession in contemporary society. These discussions are then shown to inform practice. Practice priorities are informed assessment of suspected cases, through early and statutory interventions, care for survivors, and an important focus on community engagement to prevent this form of child abuse.

\section{Key words}

\footnotetext{
${ }^{1}$ University of East London

${ }^{2}$ London South Bank University
} 
Witchcraft and spirit possession, Child abuse and protection; Religion; faithbased abuse; community engagement

\section{Subject Categories}

Child abuse and protection; Social Policy; Minority Ethnic Groups; Social Work and Social Workers

\section{Introduction}

Faith-based abuse relating to the practice of witchcraft and spirit possession is a controversial, under-researched and poorly understood form of child abuse. In the decade between the deaths of Victoria Climbié in 2000 and Kristy Bamu in 2010, the issue attracted significant publicity. Although there is little research addressing the child protection issues that arise (Simon et al. 2012), concerns have generated an extensive grey literature, including policy documents, conference papers and media reports, and these, together with the few published sources enable an assessment of current knowledge. This article critically reviews existing published and grey literature with the aims of, firstly, bringing the subject to the awareness of a social work audience, and secondly, deriving conclusions about social work interventions for this issue. Thirdly, it recognises the leading role played by social work for safeguarding children, identifying how future work should further develop knowledge, understanding and practice.

"Spirit possession" refers to a malevolent force that has entered a child and is controlling him or her, and the term "witch" refers to a child invested with evil forces to harm others (Stobart 2006 p5). Inevitably in a field characterised by limited knowledge and highly emotive content, there are significant 
controversies. These include, firstly, whether current legislation is adequate to protect children experiencing abuse related to these beliefs. Some groups, notably Africans United Against Child Abuse (AFRUCA) have lobbied for legislation prohibiting the attribution to children of spirit possession and witchcraft. New legislation for these children has been opposed in the UK by those who argue such legislation is impractical and consider that applying the existing child protection framework provides for safer practice in the current state of our knowledge (Author's own, 2011). Legal prohibition of practices that lead to cultural harm is supported by the United Nations framework for addressing cultural harm (INCO 2012) but the current UK child protection framework does not include a category of cultural harm and cases are classified as physical, emotional, sexual abuse or neglect (HMG 2017)

Secondly, there are differing views about the extent of the problem. On the one hand, UK government policy is based on current reported figures that suggest a relatively small number of cases. On the other hand, the London Metropolitan Police Service view this form of child abuse as a 'hidden crime' with larger numbers unreported than have hitherto come to light (Miller \& Bourlet 2005; McVeigh, 2014).

Thirdly, there are wider implications for relationships between cultures and communities, as the issue in Europe affects primarily migrant communities. Consequently, it is fraught with potential misunderstandings, differences of cultural emphases in highly politicised debates; the juxtaposition of the secularity of post-Enlightenment Europe with the spirituality of some non- 
European groups and cultures makes for contested territory, as in other areas in contemporary societies.

We undertook a critical review of literature (Grant \& Booth 2009) through searching electronic databases and items retrieved were assessed for relevance. Additional papers were identified from reference lists; reports from social care and international human rights organisations were assessed for authorship, source, transparency and currency. Media articles relating to high profile child abuse cases were included if cross-referenced with published and organisational based reports. Content was assessed thematically and we identified the following four themes that form our sub headings.

\section{The 'discovery' of faith-based abuse through witchcraft and spirit possession in the UK; individual cases and policy responses}

This kind of faith based abuse in the UK became known through cases of particularly extreme violence perpetrated against children. Victoria Climbié's death in 2000 sparked extensive publicity, and the subsequent Laming Inquiry (Laming, 2003) established that her carers starved Victoria to death to exorcize the evil spirits which they believed possessed her; it heard how Victoria's carer presented her as possessed to, amongst others, church pastors. Victoria's case is well known to practitioners in the UK, but the fact that beliefs in spirit possession played a significant role in her death has arguably proved harder to assimilate. 
Victoria's case was followed by others. Three-month-old baby Samira Ullah was killed in 2004 by her father, Sitab Ullah, who believed she was possessed by jinn, a term in the Islamic tradition that refers to supernatural beings who occupy a parallel world to mankind (Barker 2009; Dein, 2009). He was clearly disturbed, after personal losses, suffering from drug addiction and mental health difficulties. Of his physical abuse of Samira, he told his wife, 'I'm not hurting her, I'm hurting the thing inside her' (BBC News, 2005). Ullah said he had visited an Imam, who told the trial it was possible for people to become possessed by jinn and in such circumstances 'blessings' or 'purifications' did take place, but not usually for babies who are considered pure.

Child B was an eight-year-old girl brought to the UK from Angola after her parents were killed. She suffered considerable abuse, was starved, beaten, cut and had chilli rubbed in her eyes because her aunt and two other carers believed she was a witch. During a videoed interview, she told police, 'It's because my auntie says I have witchcraft. She dances and laughs when she hits me.' There was also evidence that she had been called a witch, ndoki, at a church event. It is possible, therefore, that members of the congregation knew about her plight, but did not, or could not intervene (Fitzgerald, 2011). Kyhra Ishaq, a seven-year-old girl, died in Birmingham in 2008 after being subject to starvation. Her stepfather, Abuhamza, believed she was possessed and aimed to starve the evil spirit that possessed her, mirroring Victoria Climbié's ordeal. One of Khyra's siblings recalled Khyra dropped down as she walked after a spirit got into her body; it was evil and it was trying to control her body because Khyra had accepted it as a friend (Fitzgerald, 2011; BBC News, 2010). 
Alongside these cases, two each from Black African backgrounds and Muslim communities, is the case of a foster parent, Eunice Spry, a white British woman, and a Jehovah's Witness, who was convicted in 2007 for inflicting sadistic punishments on her foster children over a period of 20 years, because she believed they were possessed by the devil. She beat the children, two girls and a boy, with sticks and metal bars, scrubbed their skin with sandpaper and forced them to eat lard, bleach, vomit and even their own faeces (Morris, 2007). In December 2010, Kristy Bamu, a Congolese teenager from France, was murdered by his sister's boyfriend, Erik Bikubi, aided by his sister, Magalie, whilst he and his two other sisters were staying with them in London. Bikubi and Magalie believed Kristy was possessed, and subjected him to extensive torture and beatings before drowning him in a bath (Topping, 2012).

These cases led to attempts to improve knowledge about faith-based abuse and to develop informed responses. Child B prompted the Metropolitan Police Service to set up a working group, Project Violet (Pull, 2009; MPS 2016) to discover crimes related to faith-based abuse and develop prevention strategies and initiatives. The Community Partnership Project, initiated by Local Safeguarding Children Boards in eight London boroughs, supported by the Metropolitan Police Service and Victoria Climbié Foundation (LSCB, 2016) aimed to make links with local communities.

Desk-based research by Eleanor Stobart (2006) for the Department for Education and Skills (DfES) was seen as a 'first reconnaissance' $(2006, \mathrm{p} 18)$ of cases involving spirit possession and witchcraft and relied on crime reports from 
police, social care records, reports from schools and non-governmental organisations (NGOs). The searches identified 93 cases, of which 55 lacked identifying information, or were double counted, leaving 38 cases (involving 47 children) for analysis. Most of these involved migration experiences, and most children lived within complex family structures, where the relationship and attachment with main carers was weak, disrupted or distant. Children were scapegoated or seen as being different, for example, in having a disability, or displaying challenging behaviour, such as sleep walking, wetting the bed (as did Kristy Bamu) and having bad dreams; characteristics, in other words, of emotional difficulties or additional needs.

The cases cross religions, ethnicities and cultures. Stobart found that beliefs in witchcraft and spirit possession were not confined to people of particular countries, cultures or religions. The majority of cases (20) were Christian, 5 were Muslim, 1 was Hindu, and 1 was of mixed religions; the religion of 11 cases was not known. Deliverances -also referred to as exorcisms - inflicted neglect and physical abuse; by beating ( 25 cases), burning (10 cases), starvation (10 cases), and cutting, semi-strangulation, being tied up, and having to sleep in a bath. The focus on physical abuse was accompanied by documentation of emotional abuse and neglect. Children were isolated, not being allowed to eat meals with the rest of the family, for example. Emotional abuse, including abandonment (17 cases), featured in these case records, though Stobart does not name this as such, but refers to 'unusual actions' (p.16). It is striking that 18 of the children were placed in long-term care, and that most of these families did not contest these decisions. Stobart suggests that the children involved could be identified in 
schools, as they would appear distressed, sad, isolated and withdrawn, as well as having periods of suddenly not attending. A link was found between children accused of spirit possession and places of worship, though the evidence was not well-recorded. Five children alleged being beaten in a place of worship and two were taken to a church for exorcism. Stobart also identified that practitioners did not take the children's disclosures seriously and disbelieved their accounts, raising questions of practitioner awareness. Stobart's 'initial reconnaissance', perhaps ironically, remains the only detailed study to date of the prevalence of spirit possession in the UK.

The governmental non-statutory guidance, Safeguarding Children from Abuse Linked to a Belief in Spirit Possession (DFES, 2007), drawing extensively on Stobart's report, emphasised the importance of making assessments using the existing child protection framework. It stressed reaching behind specific religious practices, since 'the underlying reasons for the abuse are often similar to other contexts in which children become at risk of poor outcomes' (DFES, 2007, p. 4). Emphasising the unacceptability of child abuse in any contexts, the guidance recognized the 'genuine beliefs' held by families and religious leaders, who can be 'deeply worried by the evil they believe is threatening them' (p.5).

Stobart (2006, p.10) expected that current attention would lead to the discovery of more cases. However, the Guidance was constructed on the basis that the number of reported cases is small, but have deeply disturbing and serious outcomes. Assumptions that the discovery of a new kind of child abuse would lead to a significant increase in reported cases turned out to be mistaken and the 
picture remains more complicated than this. Reporting problems continue to undermine attempts to gain an accurate picture as most police forces and many Local Authorities do not provide relevant statistics. Project Violet has reported increases in London, of varying degrees of severity, within the broad category of crimes linked to faith; 60 cases in 2015, an increase from 23 in 2013 and 46 in 2014 (BBC News, 2015). The relationship between reporting, prevalence and meaning constitutes a complex triangle that continues to need further exploration and evidence.

The concerns of community groups led to a Department for Education led working group which produced, in 2012, the National Action Plan to Tackle Child Abuse linked to Faith or Belief (DfE, 2012). This details strategies for engaging communities, empowering practitioners, supporting victims and witnesses, and communicating key messages. In the parliamentary processes leading up to the 2014 Children and Families Act, it was debated whether to introduce a law prohibiting the attribution of witchcraft and spirit possession to children, but this was not adopted. The current statutory basis for child protection in these cases thus rests with the original non-statutory guidance (DfES, 2007) through application of the child protection framework.

The relationship between beliefs in witchcraft and spirit possession and child abuse

The relationship between religious beliefs in witchcraft and spirit possession and child abuse is complex. Discussions that focus on African communities in 
London, in particular, and migrant communities more broadly inevitably raise questions about perceptions of cultural differences and practices, and feed into wider and contentious debates. There appears to be an irresolvable tension between preventing and identifying child abuse, driven by religious beliefs and affording toleration of religion or belief, as a protected characteristic embedded in The Equality Act 2010. Legislation that emphasises the toleration of all religious beliefs, including the Human Rights Act 1998, underpin policy and practice.

In reviewing this literature, we have identified three positions that address the tension between religious toleration and the need to protect children from abuse. Firstly, the non-statutory guidance (DfES, 2007) embeds a pragmatic distinction between beliefs and behaviour deriving from beliefs. The focus is on the outcome - child abuse in individual cases - rather than questioning beliefs held by individuals, groups and communities. This distinction has been retained by the National Action Plan to Tackle Child Abuse linked to Faith or Belief (DfE, 2012) and is held by organisations including the Metropolitan Police Service. (Author's own, 2011). This approach accounts for the asymmetry of beliefs, that are widely held, and child abuse, for which the evidence suggests few cases. However, the position is problematic as in affording toleration of beliefs, the causal connection between the application of beliefs and child abuse is avoided.

In contrast, a second position focuses on the act of witchcraft accusation, which is conceptualised as inherently abusive: this view, actively pursued by AFRUCA, critiques gaps in current legislation, whilst recognising that children accused of 
witchcraft "are often irreparably traumatised" (AFRUCA, 2015) and “dehumanised and criminalised' (Bahunga, 2013). This brings into focus the emotionally abusive potential of witchcraft accusations. However, a problematic formulation of the relationship between belief and behaviour remains; AFRUCA distinguishes between personal, private belief and its public expression, which may be impractical:

"People are free to believe in child-possession and child witches; it is only the public expression of this belief that is prohibited" (AFRUCA, 2015).

In some African countries, unlike the UK, the attribution of witchcraft to children is illegal. The paradigm that children have rights and are psychological beings, embedded in the United Nations Convention on the Rights of the Child (UNICEF, 1990), contradicts permitting the accusation of witchcraft and spirit possession, and its treatment by deliverances or exorcisms.

A third position focuses on the act of deliverance as the crucial point in which deliverance is conceptualised as always potentially abusive. Tedam (2015, p. 1408) argues that the practice of exorcism, whether by the family and carers of the child or through a church organisation is the abusive part of the 'accusation cycle' and is in contradiction with children's rights. However, it is vital to recognise different forms of deliverance. Almost all religious and spiritual communities include ritual prayer in the service of healing. The harmful aspects of deliverance rituals occur when they are used on vulnerable individuals, therefore technically all children, and individuals who have not requested such 
interventions. Deliverances that involve inflicting physical harm and where the ritual is used to address problems that are not of the spiritual realm are also considered to be at least potentially abusive.

To address the limitations in all three positions, it is important to look closely at what it means for a child to be accused of spirit possession. Accusations can be made by church officials, family members and others; deliverance, undertaken by a church official or family members, aims to prevent the accused affecting others, and to remove the spirit. In more severe cases, the belief can be held literally and concretely, so that the perpetrator has the view that 'exorcism' (deliverance) is directed against the spirit, not the child; the statement made by Samira Ullah's father illustrates this. In a Metropolitan Police Service video, Leethan Bartholomew describes how:

"with some individuals, the view is that the child no longer exists. So what they're actually doing is not harming the child. It's about trying to rid that child of an evil spirit. ... for some people, that's exactly how it is. It's that they don't actually see the child any longer. (MPS, 2016)

Thus, in these extreme circumstances, any form of physical abuse can appear acceptable to those performing the deliverance as it is the spirit not the child who is harmed. To counter these extreme forms of physical abuse, the Church Child Protection Advisory Service (CCPAS) works with pastors towards a nonviolent form of deliverance, using words, as prayers, rather than physical violence. This aims to prevent physical abuse occurring, but the meaning and 
impact of the child's emotional experience of being accused need to be considered.

Emotional abuse is, to date, an unexplored outcome from accusations of witchcraft and spirit possession, though it has been suggested that this may well be the case (DfES, 2007; Author's own, 2011; Simon et al. 2012; Bahunga, 2013). Identifying emotional abuse is therefore likely to play a significant part in preventing harm, for example when there are verbalised suspicions that there may be evil spirits at work and the child is ostracised. Accounts of individuals designated spirit possessed during childhood could be most helpful in exploring emotional abuse. There are few such accounts available yet, but Kevandi Kanda describes that the accusation can be normalised within the family:

“Children who have gone through this don't see it as abuse. They believe it is normal. If your mother tells you every day you are ugly, you are ugly. I believed I was a witch." (McVeigh, 2014).

Anane-Agyei (2009) concurs that "in many cases children also believe they are possessed" (p. 176), and this can severely impact on the self-esteem and identity of the child. Additionally, some children must live for a long time with the attribution, and its consequences for health and well-being. Anane-Agyei (2009) discusses a case where a West African 14-year-old-boy, Sebastian, was perceived by his family as possessed by kindoki, a common term throughout West and Central Africa to describe possession by malevolent spirits (Stobart 2006). Multiple family losses and the ill-fortune they represented, together with other 
relational factors in the family appeared to lead to the scapegoating of Sebastian, who started to behave as though he were possessed, including throwing himself against the wall, which he said was caused by the spirits. It took considerable work with Sebastian and his family, including placement in care to ensure his safety, and to restore his previous sense of identity.

Religious-based explanations for misfortunes and difficulties, including the child's behaviour, are frequently mentioned as a reason for attributions of possession, perhaps as a way of gaining control of life's adversities (Van Eck Duymaer van Twist, 2009). This includes when parents become fearful of the child they believe is possessed (Author's own, 2011, p.33), or when the child is perceived as different (Stobart 2006, p15). Understanding and protection can be provided through exploration of religious-based explanations for parental fears and anxieties. Exploration of the meaning of accusations in individual cases, together with affirmations of children's rights, and awareness of the emotionally abusive potential of witchcraft accusations appear to hold potential for resolving tensions between tolerance of belief and protecting children.

\section{The transnational social contexts of beliefs in witchcraft and spirit possession}

Religious beliefs can stir intense emotions, and religious differences are significant and contentious in contemporary societies. The nature of the beliefs in witchcraft, magic and spirit possession are embedded in most of the world's significant religions, and they can have powerful emotional impacts. Social work 
has tended to operate within a secular paradigm. Whiting (2008), drawing on McFadyen's (2002) concept of 'practical atheism', argues that an 'unspoken consensus' positions social work as excluding religion and faith, which can compromise cultural competence. On the other hand, holding religious views can impair child protection practice, for example, in cases of satanic abuse (La Fontaine 1998). Despite the recent growth of interest in the relationship between faith, religion and social work practice (Crisp 2017), it is not surprising that practitioners have found apprehension of witchcraft and spirit possession difficult (Stobart 2006; DfES 2007). Initial disbelief, or denial, has been a feature of the discovery of different kinds of child abuse (Kempe et al 1962; Glaser \& Frosh, 1993). Why, it is frequently asked, do such beliefs continue to have significance in contemporary societies?

Taking a transnational view (Bartholomew, 2015) brings into focus the relationship between the problem in the UK and the inequalities and marginalisation of non-western people. Postcolonialism offers an alternative to the dominant western viewpoint, addressing the human consequences of exploitation of colonised people and their lands (Young, 2003). The reflexivity of a postcolonial approach facilitates rethinking positionality; cross-national transitioning and the subsequent clash of cultural values and practices provides contexts for experiencing cultural differences. Though many faiths, countries and cultures are affected by witchcraft and spirit possession (Stobart, 2006), the experiences in African countries can be used here to illustrate. Here, increasing numbers of allegations of witchcraft and spirit possession against children and 
the severity of the outcomes have been widely reported (Bussein et al. 2011; Cimpric 2010; Molina 2006).

Modernisation and urbanisation did not lead automatically to a reduction in traditional beliefs; indeed, in fragmenting traditional family and community relationships, it is linked with the rise in accusations of child witchcraft in the region (Bussein et a.l 2011). Multi-crisis or multiform crisis are terms used to describe the catastrophic changes at economic, social, political and cultural levels (Cimpric, 2010). The consequences include displacement through civil conflicts and public health crises, such as AIDs and Ebola. Environmental devastation has been shown to increase the number of witchcraft accusations in the area (Bussein et al. 2011; Foxcroft, 2009). The changing demographic of rapidly increasing numbers of children has created pressures on families living in poverty, with more children vulnerable through being separated from parents, and they are harmed, abandoned and trafficked in alarmingly high numbers. There are reported to be between 30-50,000 street children in Kinshasa, over half of which have been accused of spirit possession (Bussein et al. 2011).

Experiences of misfortune, misery and displacement fuse with traditional beliefs to not only maintain witchcraft as a perceived solution to adversities but to increase its currency; it presents an alternative discourse to power based on Western models (Hengehold, 2009). According to Foxcroft, 'Witchcraft accusations can be seen to follow the patterns of tension and conflict in societies' (Foxcroft 2009, p3), evidenced by the "massive boom" in Pentecostal, evangelical and revivalist churches preaching "the gospel of child witchcraft, demonic 
possessions, deliverance and exorcisms" (Foxcroft, 2009). Here, Foxcroft's account (see Secker 2012), reports work by Stepping Stones, Nigeria on the effects of witchcraft accusations against children. Deliverance is central to these religious organisations, of which there has been an "explosion" since the mid 1990's (Cimpric, 2010). Changes in witchcraft practices, especially the increase in attributions of spirit possession to children, interact with social, economic and cultural changes, and corruption feeds from exploiting the fears and miseries of the population, as pastors charge for deliverances (Bussein et al. 2011). In almost all the affected countries there have been high numbers of child soldiers, who have been subject to the military's practices of making witchcraft accusations as a threat to control or exert power (Bussein et al. 2011)

How these African contexts transfer to Western European societies, especially the former colonial powers of the UK, France and Belgium, has been subject to debate. One view is that these practices are imported along with migration. Debbie Ariyo, CEO of AFRUCA, has been forthright in arguing that religious practices continue post-migration (Ariyo 2011), including through importing pecuniary exploitation:

'The pastor says there's a witch in this church today; looks around and points to a child. That means public humiliation for the family. The next step is exorcism which is not done for free. It's a money-making scam.' (BBC News, 2015) 
In the UK, the role of the churches in relation to religious practices has been unclear. It is likely that these practices are supported by some church groups whilst not by others (Author's own, 2011). The term 'rogue pastor' has been designated to a minority of individuals who maintain the practices, against the wishes of the majority. 'Churches' can be highly mobile, holding services in private spaces, rather than being static and defined by a specific building (AFRUCA, 2009). CCPAS's work illustrates that churches are reluctant to be open to questioning about the beliefs they hold, though few appear to be formally involved in deliverances (Author's own, 2011).

The complex experiences of migration have important implications for the continuity of beliefs, but these also contribute to changes away from traditional practices. Migration enriches societies, provides new opportunities for both the immigrant and host cultures, but it also brings threats to continuities of culture and customs, alongside the difficulties of assimilation into new cultures, and the losses and traumas of transition. Post-migration experiences include marginalisation, social exclusion, poverty, loss of status and discrimination. Many of the migrants from sub-Saharan Africa have been asylum seekers, fleeing 'multi-crisis', civil wars and displacement. Post-migration experiences include new inequalities in the new contexts and the resultant distress, misfortunes and lack of agency have been thought to foster traditional beliefs (Dein, 2009). Maintaining community identity involves retaining continuity of customs and places of worship can become focal points. Difficult relationships within the host country, especially regarding legal, social and cultural expectations and norms, strengthen reliance on migrant community authority figures, including church 
leaders.

Migration complicates identity and a sense of belonging: “'Home” often appears as an elusive point on the horizon' (Binaisa, 2015). A sense of belonging is a continuous project and develops in interaction with host cultures (Brah, 1996). Experiences of transition or change, generate anxieties which require containment by social structures; post-migration the structures of the host country are unknown or untrusted and alien, and offer challenge rather than remedy for difficulties and misfortunes (Casey, 2016). Traditional, familiar and accessible structures and practices can thus appear necessary for maintaining identity. Thus faith-based practices relating to witchcraft and spirit possession continue to have meaning and relevance to individuals, groups and communities outside the contexts in which they developed for complex social, psychological, cultural and economic reasons.

\section{Implications for practice: protecting children and preventing abuse}

Social work has a critical role in safeguarding children from harm through the application of these beliefs. Three key areas for practice are, firstly, identifying and responding effectively to individual cases where abuse is suspected, through early and statutory interventions, secondly, providing care for survivors who have been harmed through accusations of witchcraft or spirit possession, and thirdly, preventing abuse and reducing the factors that contribute to its occurrence, both in individual cases and within communities. 
Responding effectively to individual cases requires practitioners to recognise a spectrum of motives that parents, caregivers, faith leaders and other adults can have for behaving in harmful ways towards children. Awareness of these practices, including religious-based explanations for children's behaviour, the role of deliverances and the potential for harmful outcomes from witchcraft accusations need to be linked with exploration of the meaning of accusations in individual cases, together with strong affirmations of children's rights. Early interventions involve working with parents to address negative attributions towards the child and prevent escalation by collaboratively exploring alternative interpretations of children's behaviour and containing parental anxieties. Identification and care for survivors require specialist therapeutic work, which will often be focussed on resolving trauma whilst taking account of the spiritual dimension and the meaning of the experiences for the child. Research which assesses survivors' accounts is urgently needed, including where the child victim believes themselves they are possessed.

Practice has to engage with the complexities of faith, migration experiences, inter-cultural communications and interactions in diverse social contexts. It is imperative that practitioners can tolerate difference of cultural viewpoints and the potential for miscommunications, ambiguities across language differences (Author's own, 2014) and an appreciation of the importance of religion and belief (Gilligan and Furness, 2006). All professionals involved in this work need to have knowledge and understanding of the meaning of cultural harm.

Becoming comfortable with all these areas is gained through training and 
supervision, including reflecting on emotional experience as a practitioner in these situations (Schön, 1983). Working with cultural difference and religious beliefs and practices require reflection on one's own feelings, thoughts and attitudes. When responding to suspected cases of abuse, it is important for practitioners to acknowledge that their own views about religion are likely to influence their practice (Horwarth and Lees, 2010). Practitioners, perhaps applying 'pragmatic atheism' (Whiting 2008), may feel anxious about exploring parents' religious beliefs. They may be influenced by media coverage of religion, which has tended to focus on problematizing religious belief, including concerns about radicalisation, and child abuse committed within the church (Horwarth and Lees, 2010). Anane-Agyei pinpoints the need for self-awareness of 'one's own motives, irrational fears, obsessions' (Anane-Agyei 2009, p. 176), recognising the importance and meaning of beliefs. This counteracts overlooking the significance of religious beliefs and practices or, alternatively 'wading in' or confronting what may seem strange and different.

The discovery of new aspects of child abuse is inevitably accompanied by a desire to find ways of easily identifying cases, through recognised signs and symptoms. Though some signs can be listed as relevant to abuse arising from faith-based beliefs in witchcraft and spirit possession, it would be unhelpful to rely on these alone when making assessments. There is not, as yet, sufficient systematic research to make such an approach robust, and some potentially identifying signs can be ambiguous. A key area where knowledge is limited is that, apart from the highly-publicised cases of serious abuse, there is very little known about cases that practitioners encounter, and this is a key priority for 
further research. Therefore, current recommendations, forming the legislative basis for intervention, are that in each case a holistic assessment of the child and wider contexts needs to be undertaken making use of the child protection framework (DFES, 2007; Author's own, 2011; DFE 2012).

Engaging with and reflecting how faith and faith-based practices influence family members is an important assessment aspect. However, it is considered likely that, for abuse to take place, factors will be present that indicate the potential harm to a child through one or more of the recognised categories of abuse. These include emotional and psychological stresses, situational difficulties including poverty and social exclusion and difficult relationships in the family, including domestic abuse and problematic relationships between parents and children. Therefore, an assessment that looks closely at these and includes talking to and seeing the child will be able to relate beliefs to contexts. A key indicator to address in assessment is whether family misfortune or a child's behaviour is explained in terms of witchcraft and spirit possession. This should lead to an exploration of the meaning of misfortune or difficulty in the family and what support is helpful within informal and formal networks, including therapeutic interventions.

\section{Prevention through community engagement}

Post-colonial approaches, together with knowledge of the conflicts arising from the impacts of cross-national transitioning, can inform understanding when working with families and communities. As Tedam concludes; 
'Any preventive strategy aimed at this form of abuse and violence will require major consideration of cultural and faith-related values and ideas on the part of parents, families and communities' (Tedam 2015, p.1412)

Changing perceptions and practices in communities where the belief system is practiced has been found to be a promising approach for reducing the risks of harm (Author's own, 2011). Community engagement has the potential to engage with the lived experiences of individuals, groups and communities and to account for their socio-economic as well as cultural and religious perspectives (Author's own, 2011). The Safeguarding Children Initiative sponsored by the Trust for London worked with local communities including church organisations, to discourage the (mis) use of the belief system, to inform about children's rights and UK child protection. Engagements with church organisations, parents and youth groups enabled changes through discussions, and usually marginalised voices were heard, including those of young people and women.

For example, discussions with youth groups demonstrated that gradually over time, and with more trust, young people gave accounts of their encounters with these beliefs and revealed or adopted different views and positions. Some young people expressed considerable anger against their parents' generation and community authorities, including pastors, that children and young people should be accused of spirit possession. On the other hand, other young people felt that it is 'our own business' and should not be discussed outside the community. Yet others expressed concern that the media were using isolated incidents to attack 
Black African churches. These young people, however loyal to or questioning of community values, expressed increasing awareness of their human rights and the unacceptability of belief-based practices that harmed children (Author's own, 2011).

Similar discussions took place in other forums, including workshops for parents, church leaders and between statutory services and community representatives, facilitating expression of views at the intersections between communities, cultures, law and human rights. Workshops for parents engaged with different interpretations of children's rights, including what is tolerated and is not tolerated in UK law. Discussions of inter-cultural differences enabled voices of women and young people to be heard and for different perceptions to surface. Engagements with church leaders and pastors focussed on discussions about the legal framework of child protection but they were also seen to have important roles in mediating parents' and carers' anxieties and concerns; they have the power to make interventions that provide perspective, give explanations other than witchcraft for children's behaviour and maintain the psychological and ontological integrity of the child.

\section{Conclusions}

This article has explored the problem of faith-based child abuse related to witchcraft and spirit possession and identified key debates and concerns. These can be characterised by dilemmas and contradictions at two levels, namely, 
individual cases of abuse related to these beliefs and the cultural and community contexts where the beliefs are practiced. Through the emergence of high profile cases in the UK, it has been recognised that the application of these beliefs can have extreme consequences for children. However, the relatively small numbers of reported cases, and the limited available practice-based research means that relatively little is known about the range of cases and what are effective interventions. Therefore, practice has to proceed on the basis that a thorough and holistic assessment of each case for indicators of child abuse is necessary, and this has to be applied with understanding of and sensitivity to cultural and religious contexts.

The presence of these beliefs both in Africa and Western Europe can be contextualised not only to tradition and custom but also to changing economic, social and political contexts, and these include the often-minimised impacts of migration, including experiences of new inequalities and marginalisation. There is a strong hypothesis that there is a relationship between adverse economic, social and political contexts and the perceived need for and adherence to these belief systems. At a community level migrant and ethnic minority communities require opportunities for integration and access to resources. Community-based initiatives can promote interactions engaging with the importance of child protection and children's rights.

Training and supervision of practitioners across the sector are needed to improve recognition and responses to individual cases and through community initiatives to prevent abuse. Practitioner training needs to emphasise cultural 
awareness and competence. Finally, practice-based research is urgently needed to provide detailed, 'thick' description (Geertz, 1973) of cases to study causes and contexts alongside interventions that help children; sharing of professional experiences can provide practitioners and policy makers with knowledge on which to build informed practice. 


\section{References}

Author's own (2011)

Author's own (2014)

AFRUCA (2009) What is witchcraft abuse? www.afruca.org.

AFRUCA (2015) Why UK law should explicitly prohibit 'possession accusations', http://www.afruca.org/wp-content/uploads/2015/07/Possession-accusationsand-child-abuse-law.pdf, retrieved 09/02/2017

Anane-Agyei, A. (2009) 'The impact of spirit possession on the child's mental health and social work intervention', in La Fontaine J. (ed) The Devil's Children; From Spirit Possession to Witchcraft: New Allegations that Affect Children, Surrey, Ashgate, chapter 13, pp. 173-178.

Ariyo, D. (2011) We need to prosecute those who brand children witches, Community Care, 25/02/2011, http://www.communitycare.co.uk/2011/02/25/we-need-to-prosecute-thosewho-brand-children-witches/

Bahunga, J. (2013) Tackling child abuse linked to faith or belief, Every Child Journal, 3 (3), pp. 14-19. 
Barker, E. (2009) Introduction, in La Fontaine J. (ed) The Devil's Children; From Spirit Possession to Witchcraft: New Allegations that Affect Children, Surrey, Ashgate, pp. 1-7

Bartholomew, L (2015) Child abuse linked to beliefs in witchcraft, Transnational Social Review, 5, 2, pp. 193-198.

BBC News (2005) Baby killed for being 'possessed' 21/12/2005 http://news.bbc.co.uk/1/hi/england/london/4547544.stm.

BBC News (2010) Starved girl Khyra Ishaq's death 'was preventable' 27/07/2010 http://www.bbc.co.uk/news/uk-england-birmingham-10770907

BBC News (2015) 'Witchcraft' abuse cases on the rise http://www.bbc.co.uk/news/uk-34475424)

Binaisa, N. (2015) African migrants at home in Britain: diasporas, belonging and identity, in Sigona, N., Gamlen, A., Liberatore, G. Kringelbach, H. (eds) Diasporas Reimagined: Spaces, Practices and Belonging, Oxford, Oxford Diasporas Programme, http://www.migration.ox.ac.uk/odp/Diasporas $\% 20$ Reimagined $\% 20$ full\%20boo k\%20low\%20res.pdf

Brah, A. (1996) Cartographies of Diaspora: Contesting identities. London, Routledge. 
Bussein, N., d'Ovidio, F., Graziani, L., McCreery, K., Marfisi, L., Ramaboea, B., Rose, F. (2011) Breaking the spell: responding to witchcraft accusations against children, New issues in refugee research, Research Paper No. 197, UNHCR, The UN Refugee Agency http://www.unhcr.org/4d346eab9.pdf

Casey, l. (2016) The Casey Review: A review into opportunity and integration. London, Department for Communities and Local Government.

Cimpric, A. (2010) Children Accused of Witchcraft: An anthropological study of contemporary practices in Africa,

UNICEF, http://www.unicef.org/wcaro/wcaro children-accused-of-witchcraftin-Africa.pdf

Crisp, B., ed. (2017) The Routledge Handbook of Religion, Spirituality and Social Work, London, Routledge

Dein, S. (2009) The Jinn, Black Magic and Evil Eye Among East London Bangladeshis in La Fontaine, J. (ed) The Devil's Children; From Spirit Possession to Witchcraft: New Allegations that Affect Children, Farnham, Ashgate.

DfES (2007) Safeguarding Children from Abuse Linked to a Belief in Spirit Possession, HMG, http://webarchive.nationalarchives.gov.uk/20130401151715/http://ww w.education.gov.uk/publications/eOrderingDownload/DFES-00465-2007.pdf. 
DFE (2012) National action plan to tackle child abuse linked to faith or belief https://www.gov.uk/government/uploads/system/uploads/attachment data/file/175437/Action Plan - Abuse linked to Faith or Belief.pdf.

Fitzgerald, K. (2011) Keeping the child in mind, London Safeguarding Children Board, http://www.londonscb.gov.uk/culture and faith/training toolkit/

Foxcroft, G. (2009) Witchcraft Accusations: A Protection Concern for UNHCR and the Wider Humanitarian

Community? http://www.experts.com/Articles/Witchcraft-AccusationsProtection-Concern-for-UNHCR-and-Wider-Humanitarian-Community-By-Gary$\underline{\text { Foxcroft }}$

Geertz, C. (1973) The interpretation of cultures: selected essays. New York, Basic Books.

Gilligan, P. \& Furness, S. (2006) The role of religion and spirituality in social work practice: Views and experiences of social workers and students. British Journal of Social Work, 36 (4), pp. 617-637

Glaser, D. and Frosh S. (1993) Child Sexual Abuse, Toronto, Toronto University Press. 
Grant M. \& Booth A. (2009) Typology of reviews: an analysis of 14 review types and associated methodologies. Health Information and Libraries Journal 26, 2, p. 91-108.

Hengehold, L. (2009) Witchcraft, Subjectivation and Sovereignty: Foucault in Cameroon, Sens Public, http://www.sens-public.org/article.php3?id article=686 $2009 / 06$

Her Majesty's Government (HMG) (2017) Working together to safeguard children: A guide to inter-agency working to safeguard and promote the welfare of children, March 2015, DFE-00130-2015 https://www.gov.uk/government/uploads/system/uploads/attachment_data/fi le/592101/Working_Together_to_Safeguard_Children_20170213.pdf

Horwarth, J. \& Lees, J. (2010) Assessing the Influence of Religious Beliefs and Practices on Parenting Capacity: The Challenges for Social Work Practitioners, British Journal of Social Work, 40 (1), pp. 82-99

INCO: International NGO Council on Violence Against Children (2012) Violating children's rights: Harmful practices based on tradition, culture, religion or superstition, A report from the International NGO Council on Violence against Children, http://srsg.violenceagainstchildren.org/sites/default/files/documents/docs/In Co_Report_150ct.pdf 
Kempe CH, Silverman FN, Steele BF, Droegmeuller W, Silver HK. (1962) The Battered Child Syndrome. JAM, 181, pp. 17-24.

La Fontaine, J. (1998) Speak of the Devil: Allegations of Satanic Abuse in Britain, Cambridge, UK: Cambridge University Press

Laming, Lord (2003) The Victoria Climbié Inquiry Report, HMG, https://www.gov.uk/government/uploads/system/uploads/attachment d ata/file/273183/570.pdf

LSCB (2016) Community Partnership Project, London Safeguarding Children Board http://www.londonscb.gov.uk/culture and faith/community partnership project/accessed 21/02/2016

McFayden, A. (2002) 'Secular public theology', Crucible: The Journal of the Church of England Board of Social Responsibility, July/September, pp. 131/8.

McVeigh, K. (2014) Child witchcraft claims increasing as 'hidden crime' is investigated, The Guardian, 08/10/2014 http://www.theguardian.com/uknews/2014/oct/08/child-witchcraft-claims-hidden-crime-met-police-underreported

Miller, H., \& Bourlet, C. (2005) Act of faith? Community Care; Jul 7-Jul 13, 2005; 
1580; Business Premium Collection pg. 30

Molina, J. (2006) The Invention of Child Witches in the Democratic Republic of Congo Social cleansing, religious commerce and the difficulties of being a parent in an urban culture, Save the

Children, https://www.crin.org/en/docs/The Invention of Child Witches.pdf

Morris, S. (2007) Foster mother inflicted 20 years of sadistic abuse on three children, The Guardian,

21/03/2007 http://www.theguardian.com/society/2007/mar/21/adoptionand $\underline{\text { fostering.childrensservices }}$

MPS (2016) Metropolitan Police: Total

policing, http://content.met.police.uk/Article/Project-Violet--The-Metropolitan-

Police-Service-MPS-response-to-abuse-related-to-faith-and-

belief/1400010000897/1400010000897 accessed 21/02/16

Pull, R. (2009) 'Project Violet'; addressing the practice of faith and/or belief based ritualistic child abuse, in La Fontaine, J. (ed) The Devil's Children; From Spirit Possession to Witchcraft: New Allegations that Affect Children, Surrey, Ashgate.

Schön, D. (1983) The Reflective Practitioner: how professionals think in action London, Temple Smith. 
Secker, E. (2012) Witchcraft stigmatisation in Nigeria: Challenges and successes in the implementation of child's rights., International Social Work, 56, 1, 22-36

Simon, A., Hauari, H., Hollingworth, K., \& Vorhaus, J. (2012). A rapid literature review of evidence on child abuse linked to faith or belief. Childhood Wellbeing Research Centre. Retrieved from http://www.cwrc.ac.uk/projects/documents/Oct2012 CWRC Child Abuse linked to Faith or Belief Report FINAL.pdf

Stobart E (2006) Child Abuse Linked to Accusations of Spirit Possession and Witchcraft. Research report RR750. Department for Education and Skills.

Tedam, P. (2014) Witchcraft branding and the abuse of African children in the UK: Causes, effects and professional intervention, Early Child Development and Care, 184 (9-10), pp. 1403-1414.

Topping, A. (2012) Witchcraft trial: couple found guilty of boy's murder in London, The Guardian, 01/03/2012 http://www.theguardian.com/uk/2012/mar/01/couple-guiltyboy-murder-witchcraft

UNICEF (1990) The United Nations Convention of the Rights of the Child http://www.unicef.org.uk/Documents/Publicationpdfs/UNCRC PRESS200910web.pdf. 
Van Eck Duymaer van Twist, A. (2009) 'Beliefs in possession'. In La Fontaine, J. (ed.) The Devil's Children. From spirit possession to witchcraft: New allegations that affect children. Surrey, Ashgate.

Whiting, R. (2008) 'No Room for Religion or Spirituality or Cooking Tips':

Exploring Practical Atheism as an Unspoken Consensus in the Development of Social Work Values in England, Ethics and Social Welfare, 2, 1, 67-83

Young, R. (2003) Postcolonialism: a very short introduction, Oxford, Oxford University Press 